\title{
What does rebounding water use look like? An examination of post-drought and post-flood water end-use demand in Queensland, Australia
}

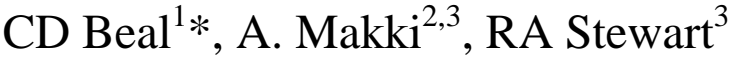 \\ ${ }^{1}$ Smart Water Research Centre \& Griffith School of Engineering, Griffith University, \\ Southport 4222, QLD, Australia \\ ${ }^{2}$ Griffith School of Engineering, Griffith University, Southport 4222, QLD, Australia \\ ${ }^{3}$ Department of Industrial Engineering, Faculty of Engineering at Rabigh, King Abdulaziz \\ University, Saudi Arabia.
}

*Corresponding author, e-mail c.beal@griffith.edu.au

\begin{abstract}
Rebounding water use behaviour has been observed in communities that have experienced plentiful water supply following a very dry period. However, the drivers of such rebounds in water consumption are varied and not well understood. Knowledge of such drivers can greatly assist managers towards proactive demand management, modelling and timely promotion of water efficient behaviours. Total and end-use residential water consumption has been tracked in south east Queensland, Australia for a sample of up to 252 homes in post-drought conditions (dam supplies growing but water restrictions continued, changed water use behaviours still 'fresh'), and during and post-flooding conditions (eased restrictions, $100 \%$ dam capacity). Data on end-use water consumption trends using nearly three years of residential water end-use data has revealed several interesting patterns of consumption such as a delayed return to pre-drought use, the influence of climate and end-use specific rebounds (e.g. indoor v outdoor use). The end-use data has helped to identify the drivers of rebounding water consumption which appear to include environmental cues (rainfall, temperature), social cues (e.g. government encouraging consumers to turn on tap) and a gradual general reduction in conservative water use behaviours. The paper concludes with a discussion of how this knowledge can be used to inform long-term demand management policy, particularly in variable climates.
\end{abstract}

KEYWORDS: smart meters, water use behaviour, demand management, water efficiency, planning, end-use studies, micro-components, outdoor use

\section{INTRODUCTION}

\section{Setting the scene}

Effective water management, be it ensuring security of supply or improving flood resilience, is never far from the top of the agenda for all tiers of government in Australia, and indeed 
globally. A number of urban and rural regions continue to experience drought in Australia, while other areas have faced their worst flooding on record. In some cases, these natural disasters have occurred consecutively in the same region. For example in South-East Queensland (SEQ), where, having emerged from one of its most harsh and protracted droughts on record, it then experienced two severe floods within the space of three years (2010-11 and 2012-13). This variability in climate, combined with high population growth, has made the tricky business of water management even more challenging in SEQ. Evolving from these challenges has been the emergence of integrated urban water management strategies from both the demand and supply perspectives.

In SEQ, policy makers have implemented a range of highly successful strategies aimed at reducing demand, including water restrictions, rebates, ubiquitous media campaigns and water use targets (Walton and Hume 2011). As a result of these strategies, residential demand reduced from around $300 \mathrm{~L} / \mathrm{p} / \mathrm{d}$ to around 120-140 L/p/d at the height of the 'Millennium drought' in SEQ (Beal and Stewart 2011). However, the prolonged wet weather which effectively 'broke the drought' has seen consistent record rainfalls and full water supply dams, which has coincided with an increase in average per capita water consumption, particularly outdoor use. Determining the drivers behind this rebound in consumption is difficult, as it may be a one or a combination of environmental (e.g. climate), social (e.g. reduced awareness, media messaging) or behavioural (e.g. increased willingness to use water) factors (Adamowski et al. 2013, Russel and Fielding, 2010, Athanasiadis and Mitkas, 2005 van Vugt. 2001). Yet determining the drivers is critical to proactively adopting water demand management strategies, particularly with the increasing variability in climate change, and subsequent water supply security.

\section{Research aims and scope}

The aims of the study were to (i) determine the trends in total water consumption for the residential properties that were participating in the South East Queensland Residential EndUse Study (SEQREUS), (ii) identify the end-uses that were influencing the more notable trends in the consumption patterns, and (iii) explore the possible drivers that were affecting total and end-use consumption over time. Both measured total and end-use data from SEQREUS households and observed total daily bulk water demand sourced from Seqwater, Queensland were used.

\section{METHODS}

\section{SEQREUS}

A total of 252 households were used in the SEQREUS, providing a good representation of SEQ households with a varying range of household occupancies, family composition and household income categories (Beal and Stewart 2011). Total water use has been recorded continuously since January $11^{\text {th }}$, 2010 to date. Within this time, eight separate water end use analysis periods of two-consecutive weeks, occurred during the SEQREUS. A summary of participant characteristics is shown in Table 1.

The SEQREUS used a mixed method, advanced water end-use measurement approach to capture and analyse water use data. Upon completion of recruitment, standard council residential water meters were replaced with modified Actaris CTS-5 water meters. These 'smart' meters measure flow to a resolution of 72 pulses/L or a pulse every $0.014 \mathrm{~L}$. The smart meters were connected to Aegis Data Cell series R-CZ21002 data loggers. The loggers 
were programmed to record pulse counts at five second intervals. Data was wirelessly transferred to a central computer and stored in a database for subsequent analysis. A representative sample of received data was extracted from the database and disaggregated into all end-use events associated with the sampled residential households using the Trace Wizard ${ }^{\circledR}$ software (Aquacraft 2010). Concomitantly with meter and logger installation, a water fixture/appliance stock survey was conducted at each participating home in order to investigate how householders interact with such stock. Further discussion on the research methods is provided in Beal and Stewart (2011).

Table 1. Selected characteristics of households in the SEQREUS sample

\begin{tabular}{|c|c|c|c|c|c|}
\hline Sample Characteristics $^{\mathrm{a}}$ & Gold Coast & Brisbane & Ipswich & $\begin{array}{c}\text { Sunshine } \\
\text { Coast }\end{array}$ & $\begin{array}{c}\text { SEQ } \\
\text { combined }\end{array}$ \\
\hline Household occupancy & 2.6 & 2.6 & 2.7 & 2.5 & 2.6 \\
\hline$\%$ Households with $\leq 2$ people & 58 & 41 & 51 & 69 & 55 \\
\hline \% Households pensioners/retired & 36 & 16 & 32 & 45 & 32 \\
\hline $\begin{array}{l}\text { \% Households with children } \\
\text { (aged } \leq 17 \text { ) }\end{array}$ & 34 & 30 & 21 & 25 & 28 \\
\hline Average age of children (years) & 8.8 & 2.7 & 4.4 & 10 & 6.5 \\
\hline $\begin{array}{l}\text { Average household income } \\
\text { (\$AUD) }^{\mathrm{b}}\end{array}$ & 73,290 & 81,630 & 87,900 & 60,070 & 75,722 \\
\hline
\end{tabular}

\section{RESULTS AND DISCUSSION}

\section{Has SEQ “rebounded” back from the drought?}

The term 'rebound' has been used been used in the context of water and energy to describe an economic phenomenon when a sector becomes more efficient and prices drop, resulting in an increase in demand and thus offsetting the efficiency gain - often termed Jevon's Paradox (Mayor et al. 2011). This is not the definition that will be used herein, rather the term rebound in this paper relates to the increase in water consumption following a sustained lower use during an period of scarcer water supply. For example, in SEQ water consumption prior to the drought 2006-8 was around $300 \mathrm{~L} / \mathrm{p} / \mathrm{d}$. A figure which decreased significantly following the effective SEQ demand management campaign as previously described. While it is not expected that per capita consumption would return to pre-drought level, due partly to smaller lot developments, in-built water efficient fixtures and changes to tariff structures throughout SEQ (Beal et al 2012, Walton and Hume 2011), there is the expectation that the low demand observed mid and post drought of between 120-140 L/p/d cannot be sustained. In this context, total demand data from Qld government sources (Figure 1) and SEQREUS data (Figure 2) clearly shows a bounce back in consumption. Through the SEQREUS it was observed that yearly averages increased from around $156 \mathrm{~L} / \mathrm{p} / \mathrm{d}$ in 2010 to $178 \mathrm{~L} / \mathrm{p} / \mathrm{d}$ in 2012. The breakdown of indoor and outdoor end-uses shown in Figures 2 and 3 indicate the concomitant in increase in outdoor demand as total demand increases.

Data from the SEQREUS is presented for each of the eight end-use analysis periods (Figure 3). Comparisons with previous end-use analyses demonstrate that consumption peaked in Sept 2012 after a prolonged period of no or low rainfall, and appears to have returned has returned to the levels that were previously observed (Figure 3a). Despite the lower sample size for Read 8 in May 2013, there is still a notably lower consumption volume. Some likely 
factors that are responsible for this observed downturn in consumption could be the environmental conditions at the time, where reduced temperatures and regular rainfall prior to the end-use reads may have resulted in less need for outdoor water activities. While the percentage of outdoor use is still greater than observed in the earlier reads (Figure 3b), the volume is much lower. Shower use also is lower than the previous two reads, but well aligned with the March (Autumn 2012) values. The 2013 data is suggesting that consumption has started to level out again and this might represent the new average in post-drought and postflood SEQ. More longitudinal data (i.e. an average rainfall summer) will be required to fully capture the absence or presence of a rebound in consumption back to the $200+\mathrm{L} / \mathrm{p} / \mathrm{d}$ usage.
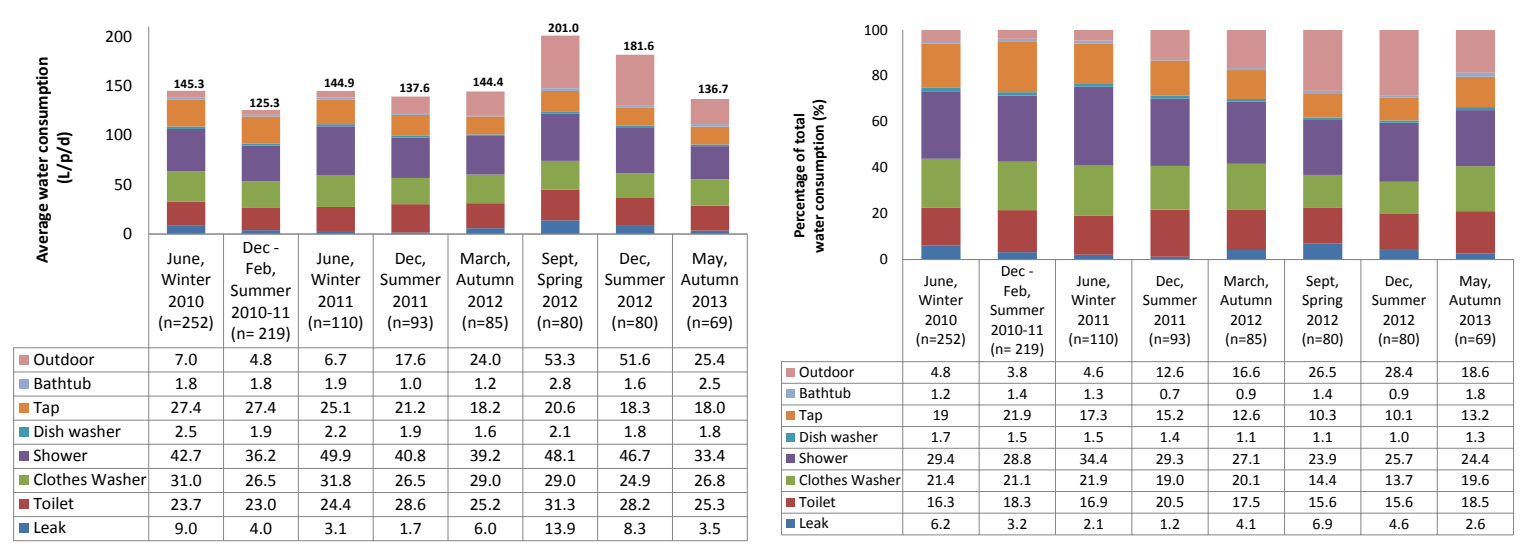

Figure 3. Comparison of average (a) per capita and (b) percentage end-uses over time (2010 to 2013)

\section{Environmental drivers of water demand}

The trend shown in the total bulk water demand pattern (Figure 1) demonstrates that once restrictions were eased, temperature and water consumption are generally positively correlated with an increase in temperature, usually corresponding to an increase in water consumption and vice versa. Similarly, rainfall and water demand were generally correlated with periods of low or no rainfall typically resulting in bulk water demand spikes (Figure 1).

In terms of measured residential end-uses the story is not quite so straightforward. Data in Table 2 indicates that when rain occurred, the mean daily household use was significantly less than the average consumption $(\mathrm{p}<0.05)$. The trends shown in Figure 4 suggest that outside use is likely to be contributing to this increase in household consumption when it has not rained for 1 or more days. The relationship between temperature and water demand, with an increase in temperature appearing clearly associated with an increase in water demand. Conversely, trends show that total water consumption is less sensitive to temperature as there is an increase in water consumption for both the high and low temperature clusters. On closer examination, the greatest increase in total water use occurred in the milder temperature and no rainfall cluster (Low Temp + No Rain) (Figure 4). These conditions are typical of late winter, early spring, where the most prolonged periods of dry weather typically occurs in subtropical SEQ. Referring back to the total water use patterns for the SEQREUS sample (Figure 2), it is this period (Aug - Nov) that exhibited the consistently higher peak days and greater proportion of outdoor water use. 
The conclusion here may be that the number of consecutive days of low or no rainfall is at least as an important indicator or determinant of higher outdoor use than the presence or absence of rainfall itself. Further, the combination of climate factors appears to be more influential on water use, as opposed to any single climate factor.

Table 2. Data from four clusters of climate conditions for the SEQREUS

\begin{tabular}{cccccc}
\hline & $\begin{array}{c}\text { Low Temp } \\
\text { + Rain }\end{array}$ & $\begin{array}{c}\text { Low Temp } \\
\text { + Dry }\end{array}$ & $\begin{array}{c}\text { High Temp } \\
\text { + Rain }\end{array}$ & $\begin{array}{c}\text { High Temp } \\
\text { + No Rain }\end{array}$ & $\begin{array}{c}\text { Overall } \\
\text { Average }\end{array}$ \\
\hline Cluster description & $<27^{\circ} \mathrm{C}+$ Rain & $\begin{array}{c}<27^{\circ} \mathrm{C}+\text { Dry } \\
\geq 1 \mathrm{~d}\end{array}$ & $\begin{array}{c}\geq 27^{\circ} \mathrm{C} \geq 1 \mathrm{~d}+ \\
\text { Rain }\end{array}$ & $\begin{array}{c}\geq 27^{\circ} \mathrm{C}+\text { Dry } \\
\geq 1 \mathrm{~d}\end{array}$ & All data \\
$\begin{array}{c}\text { Total consumption } \\
\text { (L/hh/d) }\end{array}$ & 451 & 565 & 429 & 542 & 501 \\
$\begin{array}{c}\text { Diff in means } \\
\text { compared to average }\end{array}$ & -49.8 & 65.0 & -61.3 & 41.2 & 0 \\
$\begin{array}{c}\text { Significance (one-way } \\
\text { ANOVA, 95\%) }\end{array}$ & 0.02 & 0.13 & 0.01 & 0.23 & $/$ \\
$\mathbf{n}$ & 18 & 34 & 39 & 28 & 141 \\
\hline
\end{tabular}

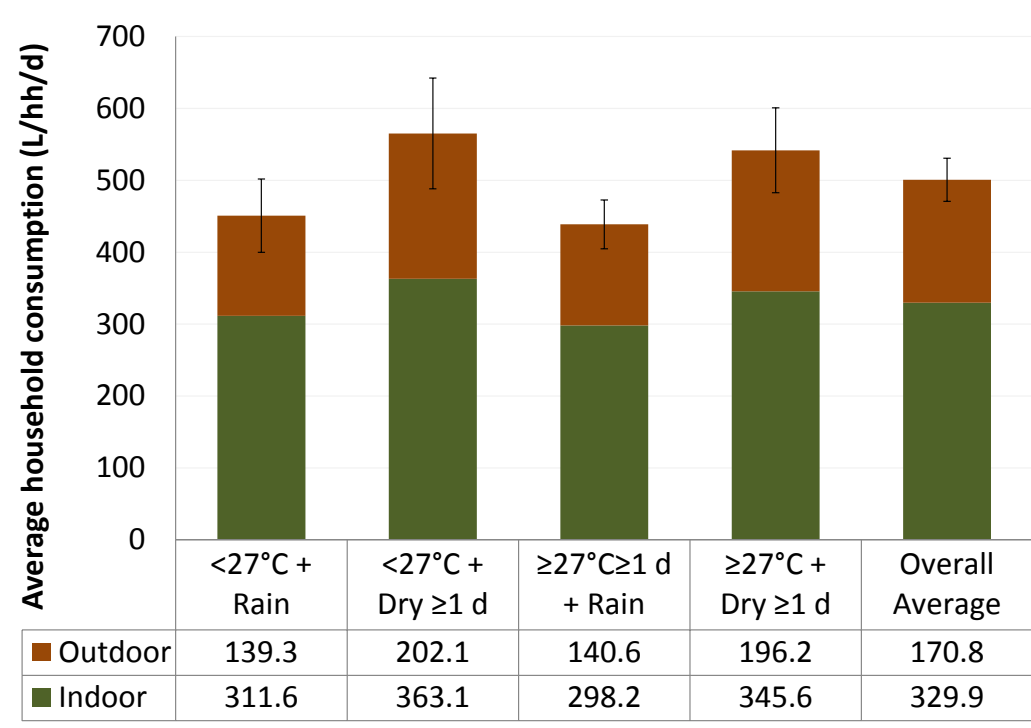

Figure 4. Trend comparison for outdoor water use

\section{Outdoor versus indoor uses}

The trend comparison of percentage of homes actively using outdoor water and the average consumption of outdoor water use activities is shown in Figure 5. Of the homes that that recorded outdoor water use, the average ranged between 14 to $56.8 \mathrm{~L} / \mathrm{p} / \mathrm{d}$ with a notable increase in average use over time (Figure 4). 


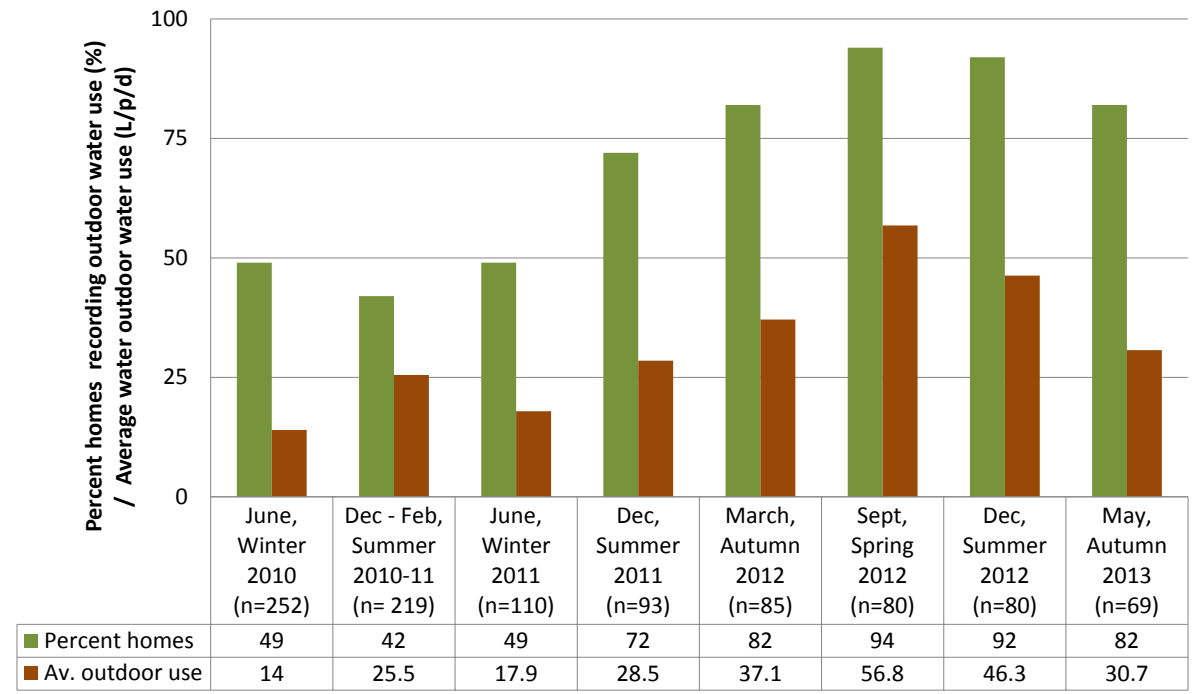

Figure 5. Trend comparison for outdoor water use

This data also demonstrates that the number of homes engaging in outdoor water use (indicated by "percent homes" on chart) also increased over time, as well as the actual volumetric use of outdoor water. This provides some evidence to suggest that attitudes and behaviours to outdoor water use and irrigation may be shifting, post-drought, towards to a more relaxed attitude and greater preparedness for people to turn on the taps outside. Furthermore, this relaxation on outdoor use coincides with generally prolonged wet weather conditions which, historically, typically sees a decline in peak outdoor water demand. Water consumption has trended downward since the "dry" spell in August and September 2012, although remains higher than 2010-2011 averages, with the number of homes engaging in water use activities outdoors continues to exceed $80 \%$ of the sample population.

\section{Mandatory versus voluntary demand management}

Both in Australia and internationally, research suggests that due to greater social awareness and increasingly widespread exposure to drought conditions people are beginning to genuinely value water as a precious resource (Jones et al. 2011, Jorgensen et al. 2009). Changing behaviour and attitudes towards water use can be done through voluntary or mandatory measures. Both the short term and long term effectiveness of these two approaches is difficult to determine as success is often dictated by interacting variables (Russell and Fielding 2010, Moss and Edmonds, 2005, van Vugt 2001). Data in Figure 6 clearly demonstrates the statistically significant impact of water restrictions on demand. However, unpacking this further, a very successful social-based community marketing was strongly promoted which was aimed at promoting voluntary water conserving behaviours (e.g. government rebate schemes, Target 140 campaigns and widespread postal distribution of water-efficient devices (shower timers). Specifically, the majority of the SBCM promotion occurred in the first half of Level 5 restrictions (Figure 6), a period that achieved the greatest percentage reduction in water demand when statistically compared $(\mathrm{P}<0.001)$ to all other levels, including Level 6 (most severe) - notwithstanding the initial introductions of restrictions in early 2005. It is worth noting too that environmental cues (rainfall and temperature) were not markedly different throughout mandatory restrictions. 
Although a preliminary assessment only, there appears evidence to further investigate the role that voluntary social drivers play in the sustained effectiveness of water conservation strategies, especially on rebounding water use in times where environmental or water scarcity cues are absent (Fielding et al. 2013, van Vugt 2001).

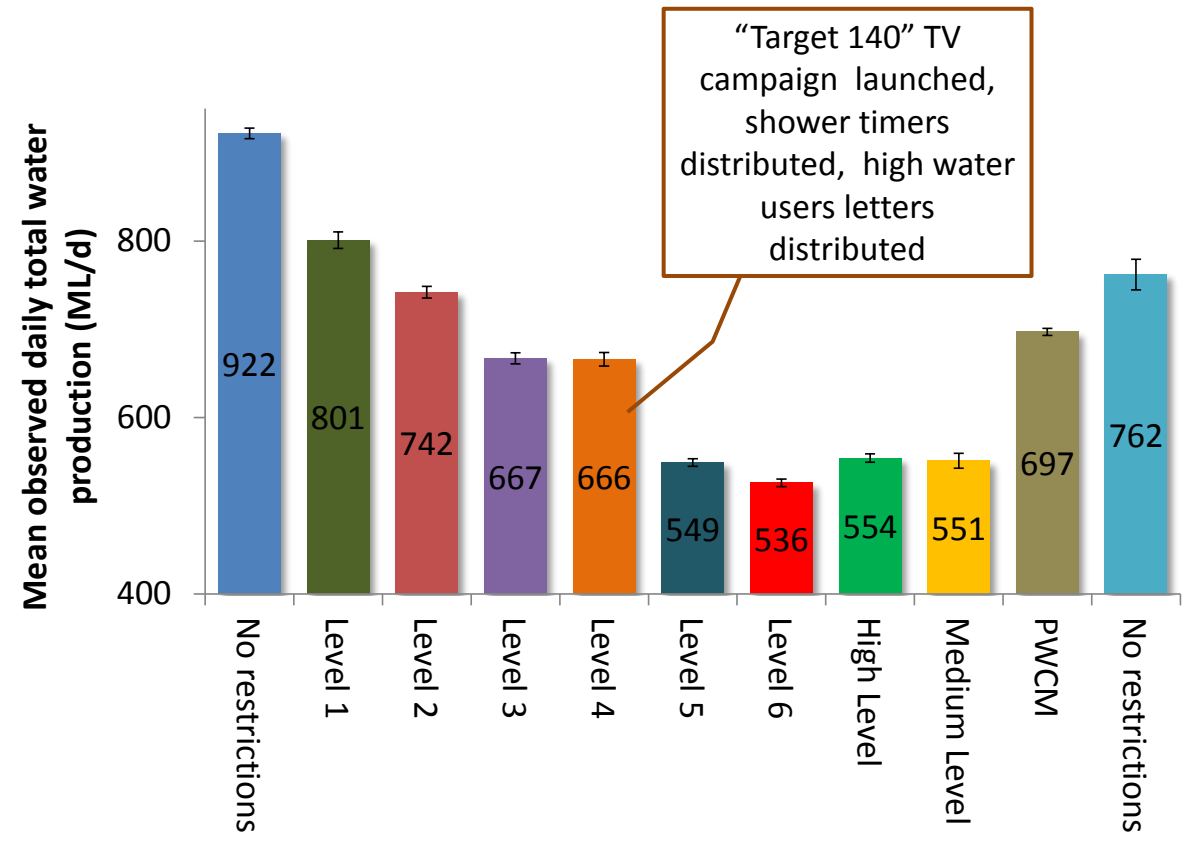

Figure 6. Bulk water demand trend pre, during and post-drought water restriction regime (95\% confidence intervals are indicated by error bars)

\section{CONCLUSIONS}

End-use analysis and total water use trends for a sample of residential homes in south-east Queensland have indicated a potential rebound in water consumption - particularly outdoor use. This increase has been attributed to both environmental and social cues including prolonged wet weather and full water supply damns, removal of behavioural cues to conserve water (absence of marketing campaigns) and removal of water restrictions. Thus, it is difficult to determine whether the observed increase in average consumption post-drought and post-floods is a result of a rebound to a "new normal" average use with the absence of social and behavioural cues to conserve water, or if it is skewed by natural variation in use prompted by periods of dry, warm weather which have coincided with elevated outdoor use.

By understanding the factors that drive upward or downward trends in water consumption, managers can adopt a proactive approach to demand management and potentially circumvent the need for restrictions or other mandatory approaches. The effectiveness of water restrictions, while not always a favoured demand management approach for water utilities, has been shown to be very effective at reducing residential demand. Another non-mandatory approach that was used in combination with enforced restrictions was aimed at behavioural shifts in water consumption prompted by community and government media messaging, Target 140 campaigns and promotion of water-efficient devices. This approach was also effective in significantly reducing demand, and may be a more favoured approach when water scarcity becomes an issue again in the future. Using behavioural interventions may also useful approach in changing the daily peak demand patterns as thus reducing the pressure on network pumping energy costs during these peak times. In the absence of immediate threats 
to water supply, the approach of using demand management to optimise water network infrastructure operating costs may well shift more strongly into focus in the near future.

\section{ACKNOWLEDGEMENTS}

The authors would like to thank the following people for their invaluable contribution to this work: Mark Askins (Seqwater), eResearch Services (Griffith University), and Lisa Stewart (Griffith University). Funding for the SEQREUS was made available through the Urban Water Security Research Alliance, Queensland.

\section{REFERENCES}

Athanasiadis, I. N., and Mitkas, P. A. (2005). "Social influence and water conservation: an agent-based approach." Computing in Science \& Engineering, 7(1), 65-70.

Beal, C., and Stewart, R. (2013). "Identifying Residential Water End-Uses Underpinning Peak Day and Peak Hour Demand." J. Water Resour. Plann. Manage., doi: 10.1061/(ASCE)WR.1943-5452.000035.

Beal, C., Sharma, A., Gardner, T., and Chong, M. (2012). "A Desktop Analysis of Potable Water Savings from Internally Plumbed Rainwater Tanks in South-East Queensland, Australia." Water Resources Management, 26(6), 1577-1590.

Beal, C., and Stewart, R. (2011). "South East Queensland Residential End Use Study: Final Report." Urban Water Security Research Alliance Technical Report No. 47, November 2011.

Bennear, L., Lee, J., and Taylor, L. (2011). "Participation incentives, rebound effects and the cost-effectiveness of rebates for water-efficient appliances." Duke Environmental Economics Working Paper No. 11-10 , 2011.

Jones, N., Evangelinos, K., Gaganis, P., and Polyzou, E. (2011). "Citizen's perceptions on water conservation policies and the role of social capital." Water Resources Management, 25, 509-522.

Jorgensen, B., Graymore, M., and O'Toole, K. (2009). "Household water use behavior: an integrated model." Journal of Environmental Management, 91, 227-236.

Maxwell, D., Owen, P., McAndrew. L, Muehmel, K., Neubauer, A., (2011). Addressing the Rebound Effect, a report for the European Commission DG Environment, 26 April 2011

Mayor, B., Hardy, L., and Lopez-Gunn, E. (2012). "Is the rebound effect / Jevon's Paradox a useful metaphort for water management?" Stockholm World Water Week, Stockholm, August 26-31, 2012.

Moss, S., and Edmonds, B. (2005). "Sociology and Simulation: Statistical and Qualitative Cross-Validation." American Journal of Sociology, 110(4), 1095-1131.

Russell, S., and Fielding, K. (2010). "Water demand management research: A psychological perspective." Water Resour. Res., 46(5).

Syme, G., Nancarrow, B., and Seligman, C. (2000). "The evaluation of information campaigns to promote voluntary household water conservation." Evaluation Review, 24(6), 539-578.

van Vugt, M. (2001). "Community identification moderating the impact of financial incentives in a natural social dilemma: water conservation." Personality and Social Psychology Bulletin, 27(11), 1440-1449.

Walton, A., and Hume, M. (2011). "Creating positive habits in water conservation: the case of the Queensland Water Commission and the Target 140 campaign." International Journal of Nonprofit and Voluntary Sector Marketing, 16(3), 215-224. 


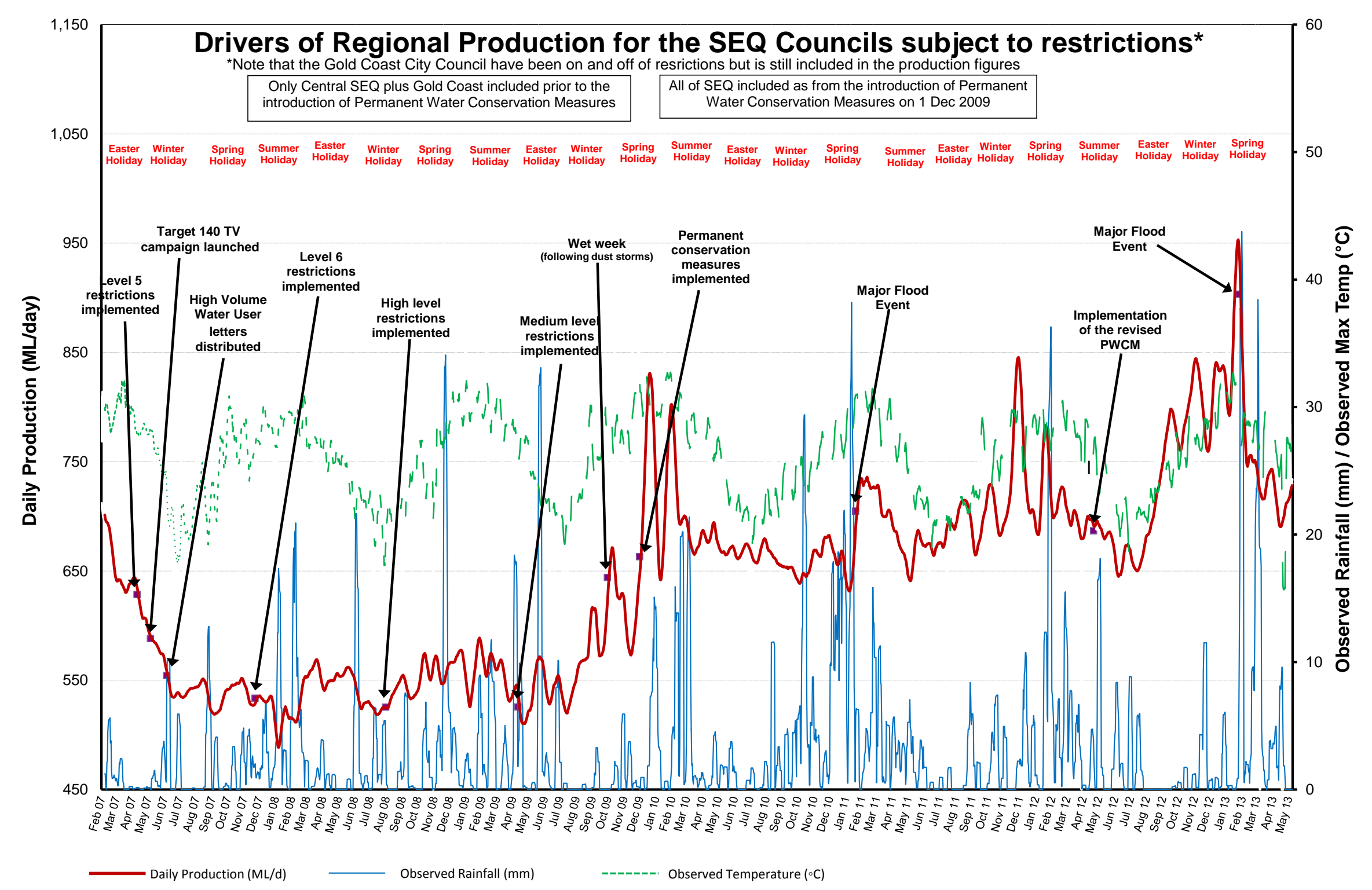

Figure 1. Two week moving average data for SEQ regions (source Seqwater, Askins 2013 


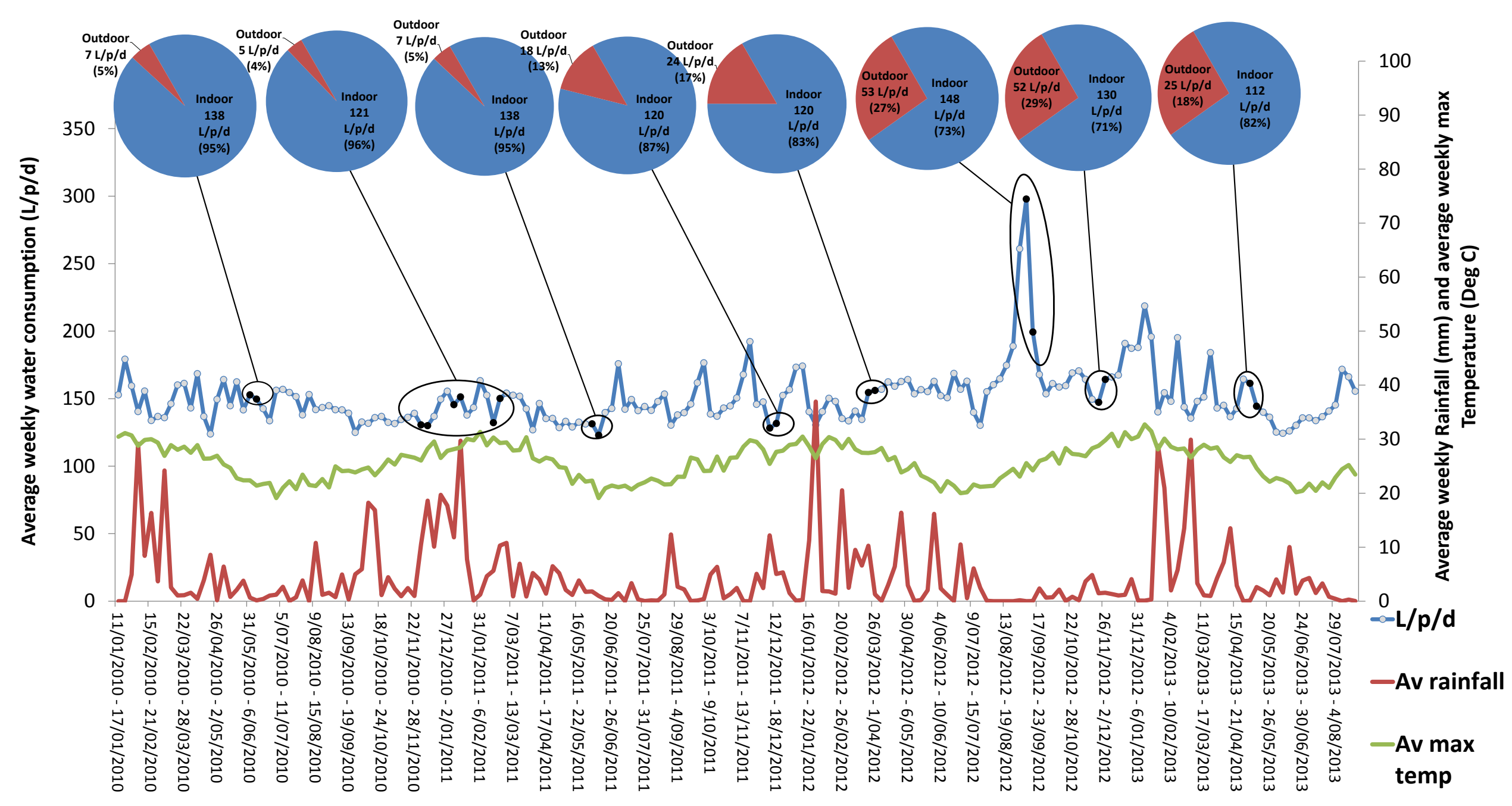

Figure 2. Trend weekly total per capita water consumption with indoor v outdoor end-use breakdown 